\title{
Análise Soroepidemiológica Retrospectiva do Vírus da Dengue no Município de Marituba, PA - Casos Notificados nos anos de 2008-2010
}

FREITAS, Heldimar Soares de ${ }^{[1]}$, FARIAS, Selma Ferreira de Freitas ${ }^{[2]}$, FECURY, Amanda Alves ${ }^{[3]}$, PbIAS, Cláudio Alberto Gellis de Mattos ${ }^{[4]}$, MOREIRA, Elizângela Claudia ${ }^{[5]}$, OLIVEIRA, Euzébio de

FREITAS, Heldimar Soares de. Et. al. Análise soroepidemiológica retrospectiva do vírus da dengue no município de Marituba, PA - Casos Notificados nos anos de 2008-2010. Revista Científica Multidisciplinar Núcleo do Conhecimento. Ano 01, Ed. 05, Vol. 02, pp. 44-58, Maio de 2016. ISSN: 2448-0959

\section{RESUMO}

A dengue é uma doença transmitida por um artrópode que acomete o ser humano e constitui um grave problema de saúde pública no Brasil e no mundo. Doença causada pelo Dengue vírus, do gênero Flavivírus. São conhecidos no mundo 4 sorotipos de dengue (1, 2, 3 e 4). O quadro clínico é caracterizado por febre clássica e hemorrágica. Essa pesquisa buscou compreender a epidemiologia da doença no município de Marituba - região metropolitana de Belém-PA - Brasil, onde foi realizado levantamento de dados no Setor de Vigilância Epidemiológica do município, referente aos anos de 2008-2010. Os dados mostram que o critério de confirmação de diagnóstico a doença (clínico-epidemiológico ou laboratorial), foi realizado por meio do isolamento viral do sorotipo. Obteve-se um total de 942 casos para investigação da dengue, sendo que o município busca trabalhar com a confirmação através do quadro clínicoepidemiológico com maior proporção e em menor quantidade para a confirmação por meio de exame laboratorial. Verificou-se ainda que o sorotipo 1, 2 e 3 são os mais predominantes no município e que o gênero feminino é o mais acometido pela doença.

Palavras Chaves: Vírus. Dengue. Soroepidemiologia. Belém. Brasil.

\section{INTRODUÇÃO}

Cotidianamente nos veículos de comunicações, estão circulando informações que expressam inúmeros episódios, que são considerados de grande importância para a população. Dentre os fatos que são mais 
tratados pelos meios de comunicação social, estão àqueles voltados para os problemas na área da saúde pública, principalmente na atualidade, pode-se citar a dengue. Desde os tempos antigos, as sociedades tinham interesse em estabelecer relações entre os fatores ambientais e a saúde, para prevenir a ocorrência e a disseminação de novos casos de doenças como é o caso da dengue (TEIXEIRA e BARRETO, 2008).

O município de Marituba está localizado na mesorregião metropolitana de Belém- Pará, integrando à microrregião de Belém. Possui um clima tropical úmido, cuja sua temperatura durante o ano atinge em média $26^{\circ} \mathrm{C}$. Os meses quentes são os compreendidos entre agosto e dezembro. Nesse período do ano a média máxima chega a $32^{\circ} \mathrm{C}$ e a média mínima atinge $22^{\circ} \mathrm{C}$. A precipitação pluviométrica média anual atinge os $2.500 \mathrm{~mm}$. A umidade relativa do ar chega a 85\% (SUDAM, 1984). O município de Marituba, como outros municípios do Brasil, tem a preocupação de prevenir contra a dengue que é uma doença que está na mídia em todo o país e que acomete e que alguns casos matam a cada ano mais pessoas, tornandose assim um grave problema de saúde pública.

A dengue é uma doença febril aguda, de etiologia viral conhecida por um arbovírus do gênero Flavivírus e pertencente à família Flaviviridae. Este gênero tem como abrangência sessenta vírus, sendo que vinte e um são patogênicos à espécie humana. Imunologicamente são conhecidos quatro sorotipos: Dengue 1, Dengue 2, Dengue 3 e Dengue 4. Na sua evolução benigna, na forma clássica, que é caracterizada, a sintomatologia apresenta-se por um quadro de febre, moleza, dores musculares intensamente principalmente nas regiões lombares e nas pernas, dores nas articulações, cefaléia, dor epigástrica, náuseas, vômitos, diarréia entre outros.

Na forma grave da doença os sintomas iniciais são parecidos aos da dengue clássica. Quando se apresenta na forma grave-hemorrágica em três a quatro dias, começam a ocorrer sangramentos internos, a pressão sanguínea diminui, os lábios ficam roxos, ocorrem dores abdominais e alternam-se períodos de letargia e de agitação, sendo que a dengue hemorrágica pode levar o individuo infectado à morte (AMABYS, 2006).

A dengue atualmente é uma das mais importantes doenças transmitida por artrópodes, insetos do gênero Aedes, que no Brasil a espécie conhecida é o Aedes aegypti. Existem outros como Aedes albopictus e Aedes africanus que são vetores secundários dos continentes asiáticos e africanos, que afetam o homem e constituem-se em sério problema de saúde pública no mundo. No Brasil especialmente nos países tropicais, onde as condições do meio ambiente favorecem o desenvolvimento e a proliferação do Aedes aegypti, este é o principal vetor.

Para isso é necessário um amplo esclarecimento para a população sobre os locais onde os insetos usam como criadouros, afim de que cada pessoa possa contribuir mais ativamente na ação, promoção e manutenção da sua saúde e da coletividade (AGUIAR, 1998). Para tanto é necessário levantar a bandeira como um alerta contra um possível surto de dengue, pois embora a sociedade tenha preocupação com a doença, ainda há muito a se fazer, principalmente em municípios que apresentam um sistema de coleta de lixo inadequado e falta de saneamento básico (DONALISIO; GLASSER, 2002).

Por conseguinte a coordenação de Vigilância em Saúde no Estado do Pará está fazendo a prevenção em municípios onde a doença aparece com mais frequência. Com base nestes dados este trabalho buscou descrever os aspectos epidemiológicos de casos de dengue no município de Marituba, na região metropolitana de Belém, no Estado do Pará- Brasil, durante o período de janeiro de 2008 a dezembro de 
2010 onde foram detectadas notificações da doença, a forma de confirmação da dengue, o seu isolamento viral e o sorotipo, e ainda relacionou-se com um comparativo entre sexo masculino e feminino, onde confirmou-se que o gênero feminino é ainda o grande alvo da doença em relação ao gênero masculino.

O dengue atualmente constitui um sério problema de saúde pública, onde o município de Marituba por estar situado em uma região com clima tropical é propício para favorecimento e proliferação de insetos Aedes aegypti, sendo que esse vetor tem como fator importância a capacidade de conviver tanto nos domicílios e peridomicílios como nas áreas rurais, fazendo com isso disseminar as epidemias de dengue (VERONESI, 1991). Com base nessas informações, levantou-se o seguinte problema: Quais os casos epidemiológicos da dengue no município de Marituba, localizado na região metropolitana de Belém?

Sendo assim a principal relevância do projeto é divulgar dados sobre a epidemiologia da dengue no município de Marituba e com isso contribuir para a conscientização da população sobre a gravidade de casos de dengue nesta área, sensibilizando- a sobre a necessidade de uma parceria governo/sociedade para combater a proliferação da dengue no município, buscando também enfatizar a responsabilidade social, resgatando a cidadania para refletir sobre a responsabilidade por si mesmo e por sua comunidade, uma vez que essa infecção viral não existe tratamento especifico apenas medicação sintomática (FUNASA, 2002).

Esse projeto buscou realizar um levantamento de casos notificados através do Sistema de Informação de Agravos de Notificações (SINAN) de pacientes com suspeita de dengue e posteriormente fazer uma correlação com os casos da doença pesquisados no município de Marituba através do Setor de Vigilância Epidemiológica do município nos períodos de janeiro de 2008 a dezembro de 2010.

Diante desse contexto, a presente pesquisa teve como objetivo geral realizar uma análise soroepidemiológica retrospectiva do vírus da dengue no município de Marituba - Pará, Brasil, por meio do levantamento de casos notificados nos anos de 2008-2010.

\section{METODOLOGIA}

O presente trabalho foi realizado por meio de pesquisas bibliográficas em livros, revistas, e artigos científicos seguidas de pesquisa de campo, sobre a epidemiologia da dengue no município de Marituba, Pará. Foi realizado também um estudo ecológico com variáveis: espacial, temporal, distribuição da doença e índice de infestação do inseto transmissor (Aedes aegypti).

A obtenção dos dados em campo ocorreu nos meses de agosto à dezembro de 2012, no setor de Vigilância Epidemiológica do Município de Marituba, através do SINAN, com análise da ficha de investigação da dengue, abrangendo o período de janeiro de 2008 à dezembro de 2010. Cabe ressaltar que o período determinado para estudo (2008-2010), ocorreu diante o fato de todos os dados investigados neste trabalho sobre dengue, já estarem disponíveis para a pesquisa, bem como notificados no SINAN. Diante das pesquisas sobre a dengue foi feito um estudo epidemiológico no município de Marituba, para sensibilizar a sociedade sobre a dengue e evitar que ocorra um surto no município uma vez que a população desconhece a gravidade da doença.

\section{RESULTADOS E DISCUSSÃO}


O município de Marituba está localizado na mesorregião metropolitana de Belém- Pará, integrando à microrregião de Belém. "Esse município tem a menor extensão territorial do estado do Pará, com 109,10 km sua coordenada geográfica: 01 ${ }^{\circ} 21^{\prime} 15^{\prime \prime}$ de latitude oeste de Greenwich (IDESP, 2009). Possui um clima tropical úmido, cuja sua temperatura durante o ano atinge em média $26 \mathrm{C}^{\circ}$, os meses quentes são os compreendidos entre agosto e dezembro. Nesse período do ano à média máxima chega a $32 \mathrm{C}^{\mathrm{o}}$ e a média mínima atinge $22 \mathrm{C}^{\circ}$, a precipitação pluviométrica média anual atinge os $2.500 \mathrm{~mm}$. A umidade relativa do ar chega a $85 \%$ (SUDAM, 1984).

As chuvas não se distribuem igualmente por todo o ano e apresenta maior incidência nos meses de janeiro a junho. Enquanto o período mais quente coincide com menor intensidade de chuva.

O município de Marituba possui aproximadamente uma população de 101,158 habitantes (IBGE, 2009) divididos em bairros e localidades que somam 30 .

A presente pesquisa teve como foco principal avaliar os dados da dengue inseridos no SINAN nos anos de janeiro de 2008 a dezembro de 2010, para compreender o perfil do agravo da doença no município de Marituba.

Os dados referentes aos casos notificados no SINAN (Gráfico 1) foram obtidos com o Setor de Vigilância Epidemiológica do Município de Marituba. Foram notificadas durante os três anos de dados coletados, as informações de 942 casos para investigação de dengue em todo o município.

Gráfico 1: Frequência por Ano da Notificaçăo de Casos de Dengue no Municipio de Marituba.

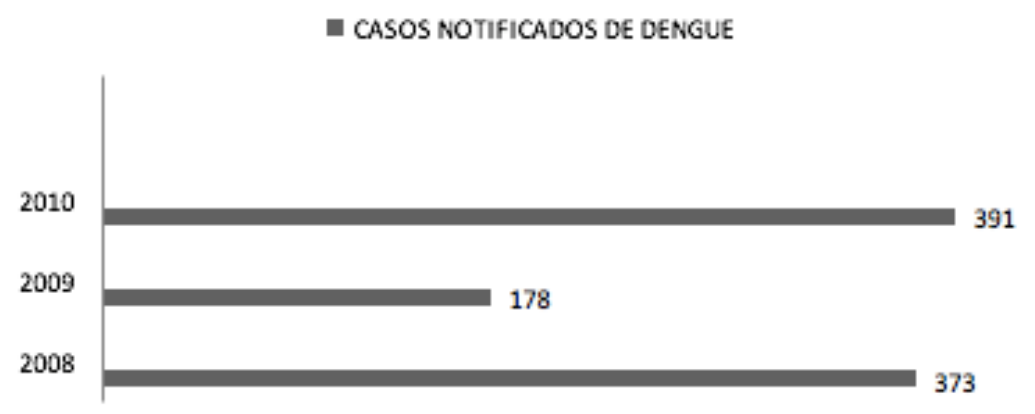

Fonte: Dados Investigação Dengue- SINAN net 2008 a dezembro de 2010.

No Gráfico1, no ano de 2008 foram investigadas nos bairros de Marituba, 373 notificações de casos de dengue sendo que no ano de 2009 esse índice diminuiu para 178, porém, não houve políticas públicas para essa redução e sim fatores que ocasionaram a falta de notificação nas Unidades de Saúde, como devido à falta comunicação entre os profissionais da área de saúde para executar o trabalho contra a dengue.

Já no ano de 2010, o número de casos saltou para 391, onde a preocupação maior ocorreu no sentido desses dados deixarem de representar apenas surtos nos bairros que compreendem o município, para ocorrer uma endemia. O que segundo Aguiar (1998). Isso é um processo progressivo que precisa ter essa 
notificação de casos de suspeita de dengue nas Unidades de Saúde no período de vigência de surtos, para que ocorram assim as investigações epidemiológicas corretamente, pois se não for tomada providências de planejamento e implementação de medidas de controle geográfico dos casos da doença a população se tornará vulnerável a epidemia de dengue.

A incidência de casos de dengue nos bairros do município de Marituba ocorre muitas vezes por falta de conscientização da própria população, bem como por falta de saneamento básico oferecido pelo poder público municipal e estadual. Isso reflete o fato do município de Marituba ter surgido há pouco tempo, uma vez que o mesmo foi emancipado em 1994, onde passou da condição de bairro de Ananindeua para município do Estado do Pará (GRANHEN, 2002).

O diagnóstico dos casos de dengue no município de Marituba é feita de acordo com dois critérios de confirmação: um clínico-epidemiológico e outro laboratorial. O Gráfico 2 mostra a investigação dos casos de dengue no município de Marituba.

Gráfico 2: Frequência por Critério Confirmaçăo da Dengue

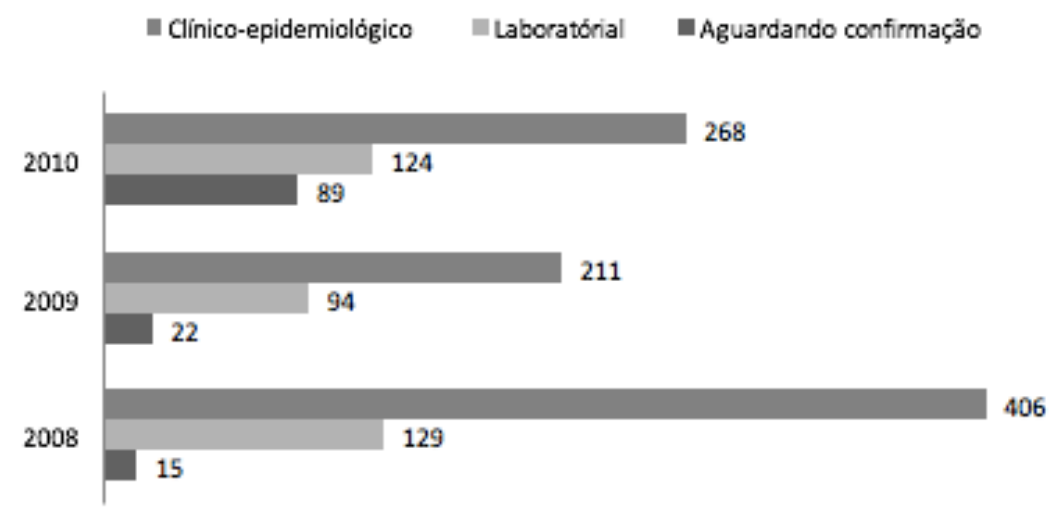

Fonte: Dados Investigaçăo Dengue- SINAN net 2008 a dezembro de 2010.

Nos anos de janeiro de 2008, a dezembro de 2010, na amostragem de dados coletados da dengue no município, ocorreu um total de 1358 casos para confirmação da doença. O gráfico apontou que em 2008, foram notificados 550 casos por critério de confirmação, sendo que 15 amostras estão aguardando confirmação, 129 casos confirmados pelo laboratório para dengue e 406 confirmação por clínico- epidemiológico.

Em 2009 houve 327 confirmações, com 22 aguardando confirmação, 94 confirmado em laboratório e 211 com confirmação clinico- epidemiológico. Uma redução significativa comparada ao ano anterior (2008), no entanto em 2010 o quadro volta a subir para 481 casos para confirmação, sendo que até dezembro de 201089 casos de notificação estão ainda aguardando para confirmação, 124 confirmados através de laboratório e 268 com confirmação clinico- epidemiológico.

A confirmação laboratorial oscila na média dos últimos três anos, 2008, 129 confirmações, 2009, 94 confirmações e 2010 com 124 confirmações. O mais preocupante da investigação de dengue para critério de confirmação é o ignorado e branco, onde durante o ano de 2008, 2009 e 2010, ainda estão aguardando a confirmação laboratorial. Ou seja, informações que o laboratório dificilmente irá proporcionar ao Setor de Vigilância Epidemiológica do município de Marituba. Esses testes sorológicos são a maneira mais 
simples e rápida para a confirmação de uma suspeita clinica. Entretanto, a interpretação de seus resultados pode, na maioria das vezes, deparar-se com alguns problemas (VERONESI, 1991).

Leão (1997) reporta-se que o diagnóstico laboratorial específico tem uma importância fundamental nas áreas sem transmissão do vetor, e também nas áreas com transmissão estabelecida, mas com poucos casos, onde deverão ser confirmados laboratorialmente. Já com a presença de casos, onde o diagnóstico é clinico e epidemiológico, o laboratório também está presente, porém em situações onde os casos se agravam para identificar o sorotipo da doença.

O quadro clínico- epidemiológico é a forma rápida de diagnosticar a doença, pois a confirmação do sintoma de dengue em área onde houve uma notificação da doença é feita através de exames laboratoriais ou em área onde o vetor e encontrado pela vigilância epidemiológica dar-se o nome de vinculo epidemiológico é quando os sintomas da dengue são apresentados em paciente onde na área o vetor se instala (FUNASA, 2005).

O isolamento viral constitui o método ideal para a determinação do arbovírus específico, responsável pela infecção. Sangue total, soro, plasma ou coágulo são os materiais de escolha para as tentativas de isolamento (FACCACIO, 2010).

De acordo com o Gráfico 3 a coleta para o isolamento viral, em janeiro 2008, até dezembro de 2010, apresentou um total de 1358 casos para diagnostico da dengue. No entanto em 2008, apenas 04 casos foram confirmados para dengue, 25 foram descartadas; 15 aguardando confirmação e 506 não foram realizados, devido os casos terem sido confirmados com quadro clínico-epidemiológico.

Gráfico 3: Isolamento Viral Segundo Ano da Notificaçào.

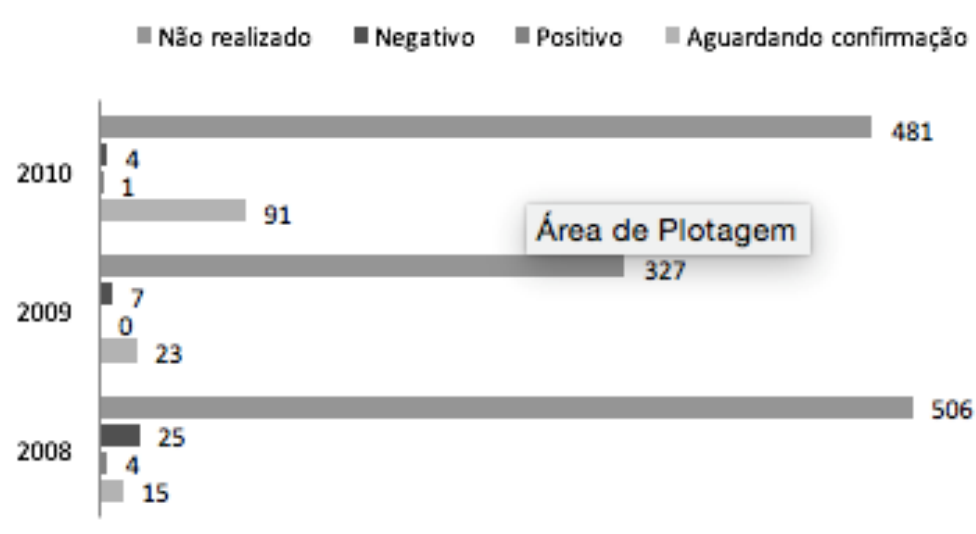

Fonte: Dados Investigação Dengue- SINAN net 2008 a dezembro de 2010.

Já em 2009 do total de 327 casos para confirmação, não houve confirmação positiva para nenhum caso; 07 casos tiveram confirmação negativa para dengue e 23 aguardando confirmações. O que podemos ressaltar é que o total de 397 casos, 297 não foram realizados testes laboratoriais. Em 2010, foi obtido um total de 481 casos para confirmação, sendo que houve apenas um caso confirmado para o isolamento viral; 04 casos negativos e 85 casos não foram realizados os testes. 
Devido à grande demanda de casos para a confirmação da doença, nem todos os pacientes tem o diagnóstico confirmado através de isolamento viral para detectar que sorotipo circula no município. $\mathrm{O}$ fator clínico epidemiológico é mais usado, porque trata de forma rápida a doença e a vigilância epidemiológica faz trabalhos de conscientização nas áreas onde tem maior concentração do vetor e casos de paciente doente nessas áreas. Para Vasconcelos (2000). A explicação mais plausível para esse fato de diagnosticar através de clínico- epidemiológico é o atendimento e a busca ativa de casos de dengue na localidade, que por sua vez se torna possível encontrar o maior número de portadores com a doença.

A Tabela 01 mostra os sorotipos circulantes do vírus da dengue no município de Marituba, de acordo com os testes laboratoriais realizados:

Tabela 1: Sorotipos segundo os anos de notificações.

\begin{tabular}{lcccc}
\hline Ano & $\begin{array}{c}\text { Aguardando } \\
\text { confirmação }\end{array}$ & Dengue 01 & Dengue 02 & Dengue 03 \\
\hline $\mathbf{2 0 0 8}$ & 546 & 01 & 03 & - \\
$\mathbf{2 0 0 9}$ & 327 & - & - & - \\
$\mathbf{2 0 1 0}$ & 480 & - & - & 01 \\
\hline
\end{tabular}

Fonte: Dados Investigação Dengue- SINAN net 2008 a dezembro de 2010.

Conforme é possível perceber, com as informações laboratoriais, constatou-se, que os sorotipos que circularam no município em 2008, foram os sorotipos 1 e 2 . Esses dados foram obtidos por meio das análises laboratoriais das 550 pessoas que apresentaram sintomas de dengue, sendo que neste ano (2008), a confirmação do sorotipo ocorreu apenas em uma pessoa para DEN 1 e três para DEN 2 , as 546 pessoas ainda estão aguardando a conclusão dos testes para identificação do sorotipo ou os dados clínicos foram suficientes para fechar o diagnóstico epidemiologicamente. No ano de 2009, foram obtidas327 amostras para verificação dos sorotipos da dengue, não houve nenhuma confirmação de sorotipo, no ano de 2010, das 481 amostras, apenas 01 foi confirmada com o sorotipo DEN3 e os demais 480 aguardam resposta dos resultados dos testes que estão sendo realizados pelo Laboratório Central do Estado do Pará (LACEN).

Esse atraso para a confirmação de sorotipo, dificilmente terá resultados concluídos, devido o tempo que foram feitas as coletas, com isso pode haver uma grande preocupação para a população do município de Marituba. Para Teixeira (1999) reporta-se que o vírus do dengue pode alterar o seu potencial epidêmico e também as suas de apresentações clínicas quando se move entre as populações. Quando a dengue acomete a sociedade ela não distingue o gênero do indivíduo. Os gráficos 4-A e 4-B, a seguir, demonstram a frequência de acometimento pela dengue em relação ao gênero masculino e gênero feminino no município de Marituba nos períodos de análises dessa pesquisa. 


\section{Grifieo 4-A: Frequescia por Genero Masculino.}
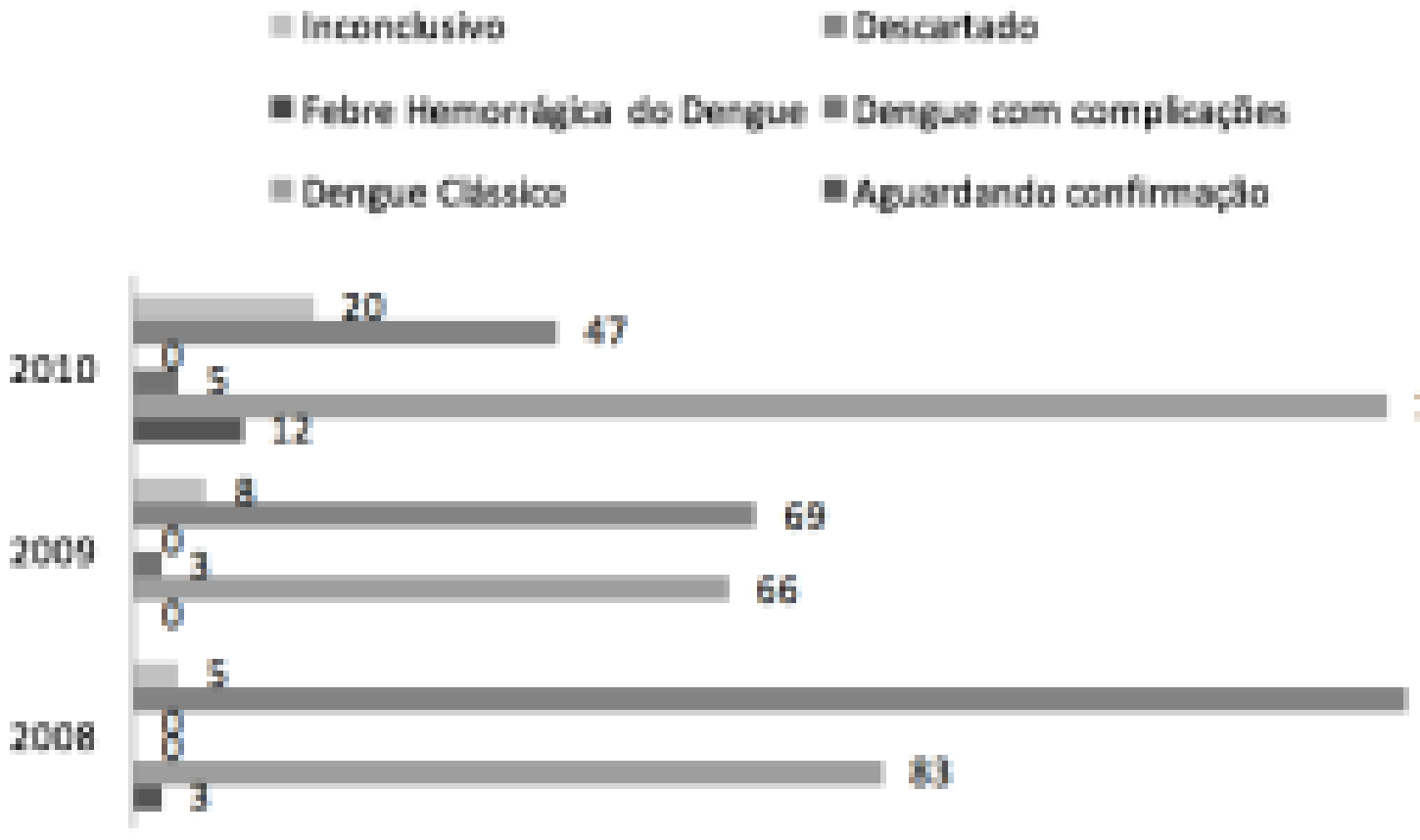

\section{Fonte: Dados Frestgasto Denzue- SINAN net 2008 a decembro de 2010.}

Observando os gráficos 4-A e 4-B, em relação ao gênero dos pacientes notificados pelo SINAN nos anos de 2008 a 2010, percebe-se que foram registradas 1358 notificações para dengue, sendo que ano de 2008, das 550 pessoas notificadas, 232 foram do sexo masculino, apresentando 03 casos para aguardar para serem notificados; 83 casos confirmados para dengue clássico; 141 descartados para dengue e 05 inconclusivos. Já para o sexo feminino no ano de 2008, foram notificados 318 casos, sendo que 04 casos estão aguardando confirmação de laboratório; 137 casos de dengue clássico; 01 caso com complicações; 173 casos descartados para dengue e 06 casos inconclusivos.

No ano de 2009 de 327 casos notificados 01 caso foi descartado devido à falta do preenchimento adequado da ficha para o SINAN, dessa forma não foi declarado o sexo do paciente. Nesse ano para o sexo masculino foram notificados 146 casos, sendo que destes, 66 foram confirmados para dengue clássico; 03 confirmações para dengue com complicações; 69 foram descartadas para doença e 08 inconclusivos. Para o sexo feminino 180 casos notificados, sendo 64 confirmados para dengue clássico; 02 casos para dengue com complicações; 100 casos para descartados para dengue e 14 inconclusivos.

E no ano 2010, foram registrados 481 casos no total, sendo para o sexo masculino 223 casos registrados. Destes 12 estão aguardando por confirmação; 139 casos confirmados para dengue clássico; 05 casos confirmados para dengue com complicações; 47 descartados e 20 inconclusivos. Para o sexo feminino foram 258 casos registrados para dengue, onde 130 para dengue clássico; 07 casos de dengue com complicações; 01 caso de óbito em consequência da febre hemorrágica do dengue; 63 descartados para dengue e 39 inconclusivos. 
Vale ressaltar que o gráfico aponta o maior número de casos notificados em pessoas do sexo feminino, e segundo dados da literatura isso é devido à vestimenta das mulheres, pois o mosquito vetor tem preferência por sugar principalmente nos pés ou nas partes inferiores das pernas, no entanto isso não quer dizer que esses insetos não possam sugar outras partes do corpo humano e de animais (NEVES, 2003).

O que se pode observar também com esses dados é que o sexo masculino, apesar dos casos notificados serem em menor número em relação ao sexo feminino, apresentam a de forma clássica da doença, e isso ocorre devido ao homem adquirir o primeiro sorotipo em virtude de alguns fatores, como por exemplo, trabalhar fora do local de seu domicilio e por usar vestimentas que dificultam a picada dos insetos. Já para o sexo feminino a preocupação é maior, porque devido à transmissão ocorrer mais no domicílio e peridomicílio, o risco de adquirir dengue é maior nas mulheres que compõem os grupos que permanecem maior tempo em sua residência (LEÃO, 1997).

É importante ressaltar também que na ficha médica de investigação da dengue, o preenchimento errado infelizmente prejudica o acompanhamento da pesquisa, pois apresentam dados inconclusivos e/ou com investigação ainda por concluir no período de janeiro de 2008 a dezembro de 2010.

Portanto, cabe destacar que essas avaliações anuais dos dados clínicos e epidemiológicos da dengue são fundamentais para o desenvolvimento e a implantação de programas de saúde pública, visando melhor combater a doença, por meio de medidas sócias educativas e preventivas no município estudado. Mas para que isso possa ocorrer é de extrema importância que os dados sejam coletados corretamente para o real conhecimento do comportamento do agravo e do perfil do paciente, contribuindo assim para um planejamento eficaz para o controle da dengue no município.

\section{CONCLUSÃO}

A dengue constitui um dos principais problemas de saúde pública em todo o país, e isso se dá devido a sua fácil expansão e um potencial para casos graves e até mesmo fatais (OPAS, 1991). Os resultados obtidos com a realização da presente pesquisa enfatizam a necessidade de uma prevenção mais eficaz no município de Marituba, principalmente em relação ao vetor da doença, uma vez que já se sabe que o índice de registro da dengue durante os anos pesquisados (2008 - 2010) apresentou-se considerável em termos de saúde pública.

Isso é demonstrado pelo critério de confirmação mais usado no município, que é a confirmação por meio de dados clínicos - epidemiológicos, com o apoio de testes de isolamento viral realizado em laboratórios capacitados, para detectar o sorotipo circulante nessa região. O comparativo do acometimento da doença em relação ao sexo também requer atenção, uma vez que mulheres são mais acometidas, por estarem mais sujeitas ao ataque do vetor. Nesse sentido também deveriam existir programas de saúde pública voltados para esse gênero, como uma melhor orientação a cerca de cuidados ambientais que devem ser adotados no lar.

Para entender a situação epidemiológica que é preocupante no município de Marituba, se faz necessário haver uma articulação entre as três esferas de governo (municipal, estadual e federal), juntamente com a própria comunidade, visando o controle permanente desta doença. Uma vez que o avanço da dengue é gerado por uma sociedade estática, é que devemos sensibilizar a população para que haja um combate coletivo, sobretudo com mais eficácia. 
No município de Marituba a dificuldade em controlar a proliferação do vetor ocorre devido às condições de saneamento básico e a grande concentração da população em área periférica. Para isso se faz necessário manter continuamente atividades educativas de esclarecimento a população sobre a doença e o combate ao vetor (GONÇALVES NETO et. al, 2004).

Portanto, as notificações no município de Marituba são ainda um problema sério que deve ser corrigido, uma vez que por falta de algumas informações não concluídas a respeito das notificações do SINAN sobre a dengue, ocorrem sérios problemas de saúde para a população. O município precisa fazer um trabalho árduo de sensibilização como ações de limpeza na cidade para eliminar o foco do inseto, orientar os profissionais da saúde para diagnosticar de forma rápida e eficaz a doença e também fazer palestras nas comunidades para prevenir e combater o mosquito transmissor da dengue. Com essas ações a população aprende a ficar atenta aos sintomas da doença e dar subsídio também ao esclarecimento para prevenir contra o mosquito Aedes aegypti.

\section{REFERÊNCIAS}

AGUIAR, Adriana Cavalcanti. Texto de Apoio Vigilância Epidemiológica. Editora: Fio Cruz, 1998.

AMABIS, José Mariano. Fundamentos da Biologia Moderna. Edição 4º, Editora Moderna, 2006.

BOSCHILIA, Cleusa. Minidicionário, compacto de biologia. $2^{a}$ edição. Ed. Rideel, 2003.

BRAGA, Ima Aparecida; Valle, Denise. Aedes aegypti: histórico do controle no Brasil. 2007.

BRASIL. Ministério da Saúde. Fundação Nacional da Saúde, Dengue: Aspectos epidemiológicos, Diagnóstico e tratamento, 2002.

BRASIL. Ministério da Saúde. Fundação Nacional da Saúde, Boletim Epidemiológico, 1999.

BRASILEIRO, Geraldo Filho. Patologia. Edição 7ª, Ed. Guanabara. Ano 2006.

DONALÍSIO, Maria Rita, GLASSER, Carmen Moreno. Vigilância entomológica e controle de vetores do Dengue. Revista Brasileira de Epidemiologia. Vol. 5, Nº 3, ano 2002.

FACACCIO, Roberto. Tratando de Infectologia, vol. 1, editora Atheu, 2010.

GONÇALVES NETO, VS, Rebelo JMM. Aspectos epidemiológicos do dengue no Município de São Luis Maranhão, Brasil, 1997-2002. Cad. Saúde pública, 2004.

GRANHEN, Jorge. A Verdadeira História de Marituba. Ano 2002.

GUZMAN, M.G. et al. Dengue Hemorrhagic fever in Cuba, 1991: A retrospectivesero epidemiologic study. American journal of tropical medicine and hygiene. Lawrence, V.42, n.2, ano 1990.

IDESP- Instituto de Desenvolvimento Econômico, Social e Ambiental do Pará- estatística Municipal de Marituba. Ano 2009. 
LEÃO, Raimundo Nonato Queiroz. Doenças Infecciosas e Parasitárias- Enfoque Amazônico, editora Cejup, 1997.

LEVINSON, Warren e JANETZ, Ernest. Microbiologia. Edição. 07. Editora: Artmed, 2005.

LOIOLA, Carlos Pratão Prates. Dengue nas Américas. Simpósio sobre dengue. Universidade de São Paulo. Faculdade de Saúde Pública. 2000. p. 48-56.

Ministério da Saúde (BR). Dengue: Fisiopatogenia e quadro clínico. FUNASA, 2005.

MONATH TP \& HEINZ F. Flaviviruses. In: FIELDS BN; KNIPE DM \& HOWLEY PM, eds. Virology, Lippincott - Raven, Philadelphia, p. 961-1034, 1996.

NEVES, David Pereira. Parasitologia Humana, Editora Atheneu 10 Edição. 2003

OLIVEIRA, Alexandre R. Diogo. Editora. Biologia e Saúde, Rio de Janeiro, 2000.

ORGANIZAÇÃO PANAMERICANA DA SAÚDE. Diretrizes relativas à prevenção e ao controle da dengue e da dengue hemorrágica nas Américas. 1991. Relatório da Reunião sobre diretrizes para a Dengue.

SOARES, José Luís, Programa de Saúde, Editora Scipione, 2º edição, 1994.

TEIXEIRA, Maria da Glória; BARRETO, Maurício Lima; GUERRA, Zouraide. Epidemiologia e medidas de prevenção do Dengue. 1999, vol.8, n.4.

TEIXEIRA, Maria da Glória; BARRETO, Maurício Lima. Dengue no Brasil: situação epidemiológica e contribuições para uma agenda de pesquisa. Estud. av. vol.22 no. 64, São Paulo. Dec. 2008

TRABULSI, Luiz Richard. Microbiologia. Edição. 05. São Paulo. Editora Atheneu, 2008.

VASCONCELOS, Pedro Fernando da Costa ET al. Epidemia de dengue em Ipupiara e Prado, Bahia. Inquérito soro-epidemiológico. Revista da Sociedade Brasileira de Medicina Tropical. Ano. 2000.

VERONESI, Ricardo; Doenças Infecciosas e Parasitárias. Ed. 08. Editora Guanabara-Koogan, 1991.

${ }^{[1]}$ Biólogo. Especialista em Microbiologia pela Faculdade Ipiranga, PA.

${ }^{[2]}$ Acadêmica de Enfermagem da Faculdade Metropolitana da Amazônia.

[3] Doutora em Doenças Tropicais. Docente e Pesquisadora da Universidade Federal do Amapá, AP. Pesquisadora do Programa de Pós Graduação do Núcleo de Medicina Tropical da UFPA.

${ }^{[4]}$ Biólogo, Doutor em Teoria e Pesquisa do Comportamento. Docente e Pesquisador do Instituto Federal do Amapá - IFAP. 
${ }^{[5]}$ Psicóloga. Mestre em Teoria e Pesquisa do Comportamento. Docente da Universidade do Estado do Pará - UEPA. Pesquisadora do Programa de Pós Graduação do Núcleo de Medicina Tropical da UFPA.

[6] Biólogo. Doutor em Medicina/Doenças Tropicais. Docente e Pesquisador na Universidade Federal do Pará - UFPA. Pesquisadora do Programa de Pós Graduação do Núcleo de Medicina Tropical da UFPA. (Autor correspondente).

\section{PUBLIQUE SEU ARTIGO CIENTÍFICO EM:}

https://www.nucleodoconhecimento.com.br/enviar-artigo-cientifico-para-submissao 